Australian Journal of

Crop Science

\title{
Potential of Colletotrichum typhae H.C Greene mycoherbicide for bio-control of Southern cattail (Typha domingensis Pers.) plants
}

\author{
Cláudio Belmino Maia ${ }^{1}$, Paulo Alexandre Fernandes Rodrigues de Melo ${ }^{1}$, Robert Weingart Barreto ${ }^{2}$, Luiz \\ Antônio Maffia ${ }^{2}$, 0 correto é Kedma Maria Silva Pinto ${ }^{3}$, Ilka Márcia Ribeiro de Souza Serra ${ }^{1}$, Antonia Alice \\ Costa Rodrigues ${ }^{1}$, Mário Luiz Ribeiro Mesquita ${ }^{4}$, Aline Priscilla Gomes da Silva ${ }^{5}$, Janaina Marques Mondego ${ }^{1}$ \\ ${ }^{1}$ Universidade Estadual do Maranhão, Centro de Ciências Agrárias, Programa de Pós-Graduação em Agroecologia, CP \\ 65.055-098, São Luís, MA, Brazil \\ ${ }^{2}$ Universidade Federal de Viçosa, Centro de Ciências Agrárias, Departamento de Fitopatologia, Brazil \\ ${ }^{3}$ Universidade Federal Rural de Pernambuco, Programa de Pós-Graduação em Produção Agrícola, Brazil \\ ${ }^{4}$ Universidade Estadual do Maranhão, Programa de Pós-Graduação em Agricultura e Ambiente, Brazil \\ ${ }^{5}$ Michigan State University, Department of Horticulture, East Lansing, MI 48824, United States
}

*Corresponding author: pauloalexandrefernandes@outlook.com

\begin{abstract}
The anthropic interference in aquatic ecosystems favors the disordered colonization of $T$. domingensis, damaging the production of hydroelectric power and river traffic. Because of this, studies report the efficacy of fungal mycoherbicides, with control rates reaching as high as $90 \%$. Thus, the objective of this study was to evaluate the potential of $C$. typhae as a mycoherbicide in bio control of $T$. domingensis, at in vitro and greenhouse conditions. 107 samples of symptomatic $T$. domingensis leaves were collected in flooded areas of rivers in Brazil, with identification and isolation of the collected fungal species. The concentration of inoculum was determined to evaluate the incidence and severity of the disease, the influence of temperature on mycelial growth and conidia germination, the effect of temperature and leaf wetness period on $T$. domingensis infection by $C$. typhae and the host range test in vitro. The growth of the colonies of $C$. typhae was higher at 25 to $30 \stackrel{\circ}{ }$. There was no interference of the photoperiod on germination of the spores, but the highest percentage of germination was occurred at $20 \stackrel{\circ}{ } \mathrm{C}$. The influence of environmental conditions on infection of inoculated leaves of $T$. dominguensis revealed that at $15 \stackrel{\circ}{\circ}$ and the period of leaf wetness of 48 hours the highest incidence of the disease was observed, as well as the severity for the same period of leaf wetness. The specificity test showed that $C$. typhae is specifically pathogenic to $T$. domingensis. This the first report of the occurrence of this pathogen in aquatic macrophytes of this species and in $T$. domingensis, a potential mycoherbicide for the control of this aquatic weed.
\end{abstract}

Keywords: Biological control; Aquatic macrophytes, Leaf wetness.

Introduction

Typha domingensis Pers. is an invasive macrophyte found in the Americas, Europe, Africa, Asia and Oceania, being considered as a native species of South America, occurring throughout Brazil (Oliveira et al., 2017). It is propagated either by seeds or vegetatively, by rhizomes, with vigorous growth by the decomposition and assimilation of organic matter as a source of nutrients, reaching about seven tons of rhizomes per hectare (Rangel-Peraza et al., 2017). Thus, T. domingensis is used as a biological filter for urban sewage, industrial effluents rich in heavy metals and erosion control in drainage channels and reservoir banks (Bonanno and Cirelli, 2017).

However, anthropic interference in aquatic ecosystems favors the colonization of $T$. domingensis, which may hinder the production of hydroelectric power, river traffic and agricultural irrigation (Lagerwall et al., 2017). In the United States, this macrophyte accounts for the degradation of almost 12.000 ha

${ }^{1}$ of Florida marshes, due its aggressive growth in response to eutrophication by nitrates and phosphates from agricultural and urban waste and frequent fires (Smith and Newman, 2001). In Brazil, it is estimated that the intense growth of $T$. domingensis in reservoirs of the country's hydroelectric dams extends to about $300 \mathrm{ha}^{-1}$ in the water mirror. These changes contribute to the reduction of water quality and biodiversity patterns in environments colonized by this species (Pompêo, 2017). 
Up to a certain limit, the development of aquatic vegetation can be considered harmful in several ecosystems (Malaspina et al., 2017). In order to reduce the environmental, social and economic impacts of hydrophytic plants, mechanical and biological control have been used (Pitelli et al., 2008; Diao et al., 2013). The use of chemical herbicides is another option to control aquatic weed macrophytes, which is allowed in countries like the United States. Its application is controversial in European countries and Brazil (Garlich et al., 2016). This is due to the low acceptance by society, due to the excessive use of toxic agrochemicals to different plant species, besides the low number of registered products (Harding and Raizada, 2015).

Thus, the use of weed control methods with a higher degree of specificity that reach only the target species constitutes viable alternatives (Heydari and Pessarakli, 2010). Among these, the mass production of microorganisms intended for the formulation of mycoherbicides has been shown to be effective in weed management in several parts of the world (Singh et al., 2016). Research results have shown the efficacy of several commercial mycoherbicides made with fungi of the genus Colletotrichum, with control rates reaching $90 \%$, such as the use of Colletotrichum truncatum (Schwein) for Sesbania exaltata (Raf.) Rydb. ex AW Hill., Colletotrichum acutatum (Sim.) in Hakea sericea Schrad. and Colletotrichum gloeosporioides Penz. (Sacc.) for the control of Aeschynomene virginica L. (Harding and Raizada, 2015).

Research on microorganisms that can replace mycoherbicides establishes optimal culture condition for mass and durable production of the inoculum in artificial culture (Jiménez and Villasana, 2009). The pathogen should be genetically stable and specific to generate rapid and high disease level, with consequent death or suppression of the target plant, and should not present pathogenicity to crops of agricultural interest (Cimmino et al., 2015). Thus, it is necessary to study the pathogen and its interaction with the host, as well as the conditions that predispose the plant to the pathogen, since climate variables such as temperature may influence both infection and colonization of the pathogen (Kusari et al., 2012). In addition, host specificity and preference has been a criterion in research with Colletotrichum species for the biological control of plants. Some species of these pathogens are capable of infecting single hosts and, conversely, there are also Colletotrichum species capable of infecting multiple host species (Doyle et al., 2013).

In recent years, little has been studied about these parasitic relationships between fungi and aquatic weed macrophytes. However, satisfactory results were obtained in studies with the Eichhornia crassipes Mart. Solms and Cercospora rodmanni (Harding and Raizada, 2015). Another important result was reported by Pitelli et al. (2008), showing that fungi of the genus Colletotrichum have been receiving attention as potential mycoherbicides, suggesting that these pathogens have specific enzymes that promote infection and degradation of the plant cell wall. This study is the first report of the occurrence of $C$. typhae in aquatic macrophytes in Brazil. The objective of this study was to evaluate the potential of $C$. typhae as a mycoherbicide for control of $T$. domingensis, at in vitro and in greenhouse condition.

\section{Results and Discussion}

The microflora associated with $T$. dominguensis plants was identified as Colletotrichum typhae, Cercospora sp., P. dichota, Phoma sp., C. typharum and Stenella sp.. But only the $C$. typhae isolates were pathogenic to $T$. domingensis at the concentration used in the pathogenicity test. For this reason, the other tests were carried out only with C. typhae, to verify their bioherbicidal capacity on $T$. dominguensis.

After analyzing the pathogenicity of the isolate at different inoculum concentrations, a development pattern of the anthracnose symptoms was observed at the concentration of $2.5 \times 10^{6}$ spores $/ \mathrm{ml}$ on the eighth day after inoculation. Thus, the infection started with lesions slightly visible although homogeneously distributed in the lap of the plants reaching a leaf area of $19 \%$. In this study, levels from 0 to $100 \%$ of injured leaf area were identified, and the images obtained aided the evaluation of the other trials.

The conidia produced by Colletotrichum sp. are survival structures. They are important in infection of the host and in the propagation of these pathogens. Despite its relevance to the fungal life cycle, the conidia biology has not been extensively investigated. In this study, the first description of the $C$. typhae conidia germination, whose ideal thermal condition was verified at a temperature of $20{ }^{\circ} \mathrm{C}$, was observed. The lowest spore production index was observed at the temperature of $35{ }^{\circ} \mathrm{C}$ (Fig.1A). Similar results were obtained by Estrada et al. (2000), who found that the optimal temperature for sporulation of $C$. gloeosporioides was between 20 and $25^{\circ} \mathrm{C}$.

However, Poltronieri et al. (2013) reported that the optimal temperature for conidia germination may vary for different species of the genus Colletotrichum sp.. Harding and Raizada, (2015) observed that the germination of Colletotrichum musae B \& MAC conidia is stimulated between 27 and $30{ }^{\circ} \mathrm{C}$, while Couto and Menezes (2004), demonstrated that the Colletotrichum coccodes Wallr. sporulation occurs between 20 and $30{ }^{\circ} \mathrm{C}$ and for Colletotrichum lagenarium (Pass.) Ellis \& Halst. at $16^{\circ} \mathrm{C}$.

The temperature data on the disease incidence were adjusted to the cubic regression model for mycelial growth and conidial germination variables. The conidia germination and the temperature range between 25 and $30 \circ \mathrm{C}$ provided the highest C. typhae mycelial growth (Fig.1A and 1B).

The inhibitory effect of temperature on fungi growth is variable, but most pathogens show better development at 20 to $25{ }^{\circ} \mathrm{C}$. For C. acutatum, McKay et al., (2009) reported that the optimum temperature for mycelial growth was $25{ }^{\circ} \mathrm{C}$. Harding and Raizada, (2015) stated that elevated temperatures 

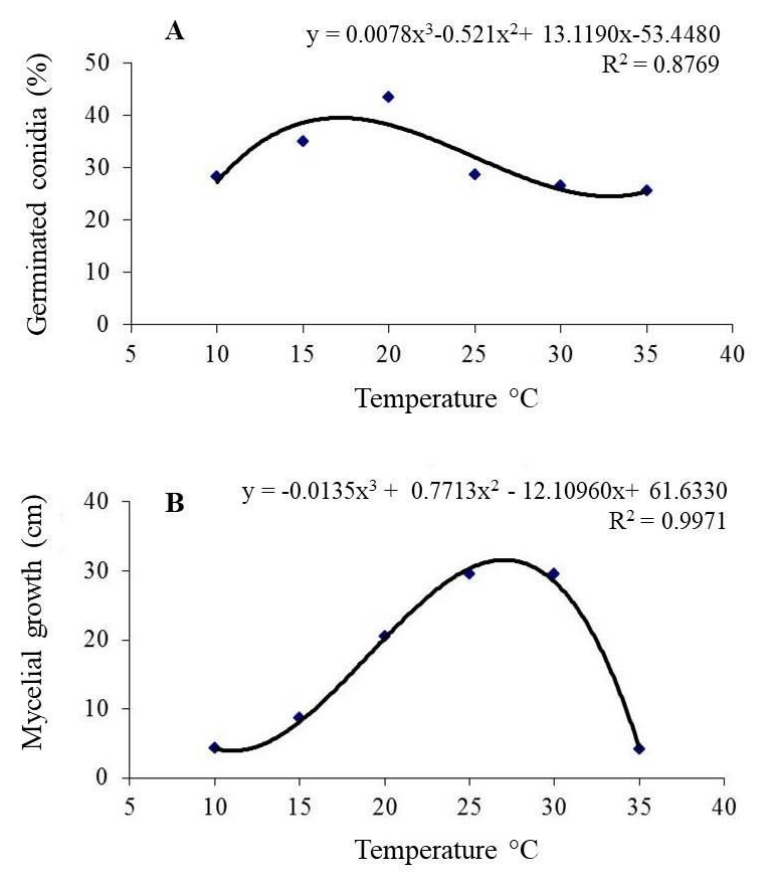

Fig 1. Effect of different temperatures, on C. typhae conidia germination in agar-water (A) and micelial growth in VBA (B). Viçosa-MG, UFV, 2019.
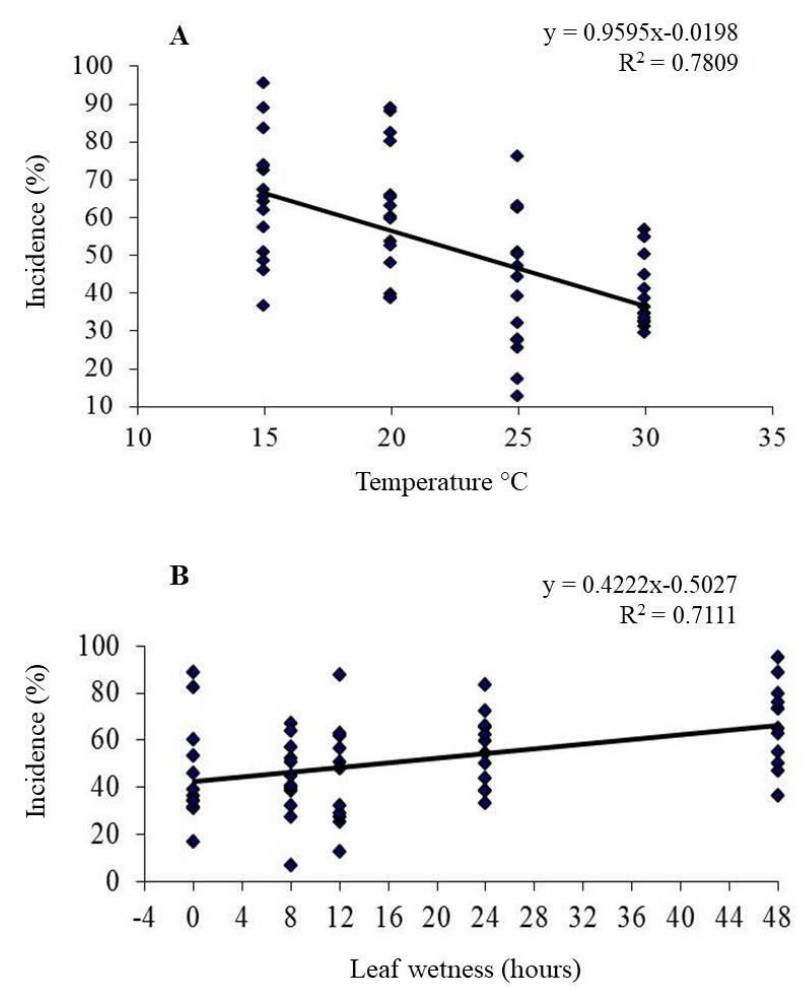

Fig 2. Influence of temperature (A) and leaf wetness period (B) on T. domingensis infection by C. typhae. Viçosa-MG, UFV, 2019. 


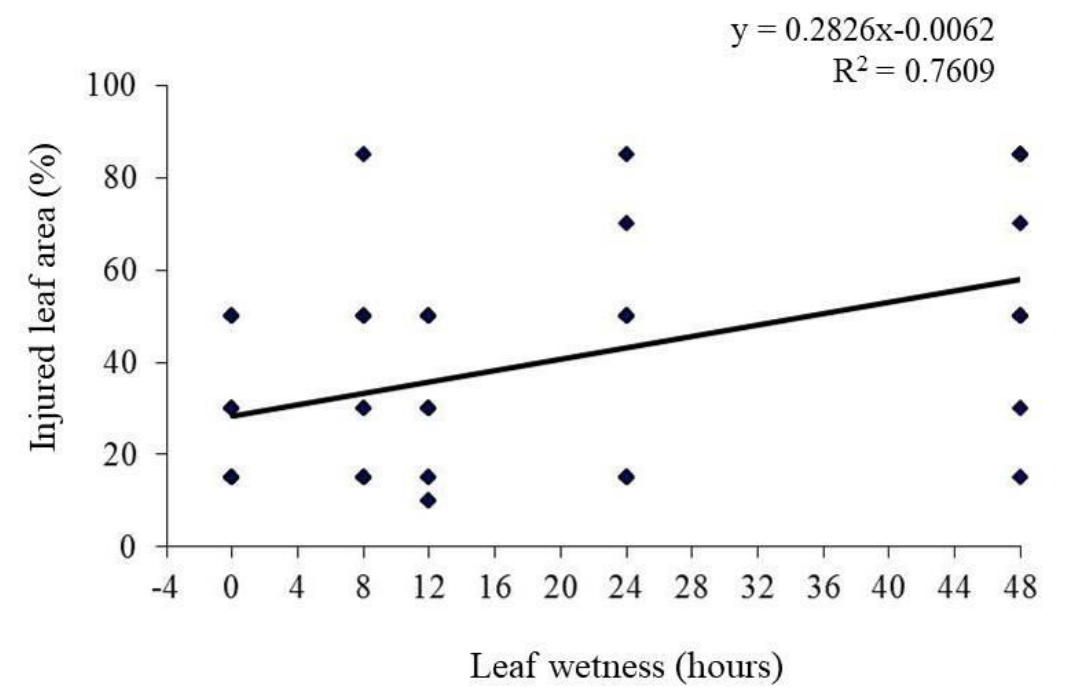

Fig 3. Effect of leaf wetness on the severity of the desease caused by $C$. typhae in plants of $T$. domingensis, in the greenhouse. Viçosa-MG, UFV, 2019.

around $35.5{ }^{\circ} \mathrm{C}$ paralyze C. gloeosporioides mycelial growth, corroborating with the results obtained in this study.

The relationship of a pathogen to the host may vary from one host to another. In this case, the interactions between this pathogenetic systems are still not well understood (Doyle et al., 2013). Due to this interaction, studies on microorganisms for biological control of plants aim to establish ideal culture conditions for mass and durable production of the inoculum in artificial culture (Jiménez and Villasana, 2009). Climate variables such as temperature, influences the rate of fungal reproduction, physiological conditions of the host, growth and aggressiveness of pathogens. Thus, the knowledge of the interaction of the pathogen with environmental factors has a practical meaning, since the environment can alter its pathogenicity (Terefe et al., 2015).

The disease incidence data, submitted to different temperatures and leaf wetness periods, were adjusted to the linear regression model, showing a decreasing incidence in relation to the increase in temperature, and increasing in relation to the leaf wetness period (Fig.2A and 2B). The temperature influenced the formation of chlorotic lesions on the leaf blade surface of $T$. domingensis plants, except for $20 \%$ of the plants that were kept at temperatures of 15,20 and 30 ${ }^{\circ} \mathrm{C}$. These plants showed no symptoms of anthracnose in the first evaluation that occurred eight days after inoculation. It was also found that at 15 and $20^{\circ} \mathrm{C}$, the maximum incidence of the disease was 95 and 90\%, respectively (Fig.2A). During the evaluations of leaf wetness periods, we observed that after the period of 48 hours, the duration of the leaf wetness period favored the incidence of $C$. typhae with maximum percentage rate of $95 \%$ of symptomatic plants (Fig.2B).

With regards to the severity of the disease, we observed that at zero hour of leaf wetness, small lesions near the lap of the plants were contacted, whereas in the higher parts of the plants these lesions were very scarce (Fig.3). Lima et al. (2017) evaluated the development of phytopathogens. They reported the absence of disease in zero wetness, indicating that the incidence of the fungus Puccinia kuehnii may be related to the need of free water on the leaves of the inoculated plants and a wetness period for at least 12 hours for fungal infection to occur. However, in this study, the presence of anthracnose symptoms in the lap of $T$. domingensis plants at zero wetness period with a rate of $85 \%$ is probably due to the proximity of these areas to the water in the pot, where it was possible to create a microclimate that has favored conidial germination, infection and lesion development.

Spores of most pathogenic fungi require free water for hours at the host surface for germination and consequent penetration. The increase in disease intensity accompanies the wetness period up to a certain threshold, from which the maximum amount of disease is reached and it is no longer influenced by additional wetness periods (Bedendo and Amorim, 2011). According to Lima et al. (2017), from a certain concentration of infection points, lesions that form first, may hinder the development of others that result from subsequent infections. However, in the present study the highest progression of both disease incidence and severity was detected with increasing time duration of leaf wetness (Figs.2B and 3).

The highest severity of symptoms was observed in 8,24 and 48 hours leaf wetness periods, with rates of 82,85 and $88 \%$, respectively. There is little research on the epidemiology of anthracnose caused by $C$. typhae. In addition, the results obtained in this study are the first report of this disease in $T$. domingensis plants, so further studies are probably needed to confirm these results (Fig.3).

Climate variables such as temperature and precipitation influence the development of anthracnose symptoms. Under 
high temperature conditions, pathogens can grow rapidly and severe outbreaks of disease are expected in environments with high relative humidity (Moral et al., 2012). According to Soares-Colletti and Lourenço (2014), the infection rate is high in the range of 15 to $30 \stackrel{\circ}{C}$ for $C$. gloeosporioides, with the ideal temperature around $25 \stackrel{\circ}{ } \mathrm{C}$. However, for $C$. acutatum like C. typhae a maximum incidence of this pathogen was occurred at $20^{\circ} \mathrm{C}$. Regarding the wetness period, the results obtained in this study with $C$. typhae coincide with those found by Soares, Lourenço and Amorim (2008), who reported that the greater severity of anthracnose caused by $C$. acutatum and $C$. gloeosporioides was high after 48 hours.

In this study, during the evaluation of the incidence and severity of anthracnose in plants of $T$. domingensis, we verified that the amount of hours of the wetness period needs to be continuous reaching its peak after 48 hours. In order to cause infection in plants, $C$. typhae probably requires several short wetness rather than a single long period. Among the factors that may restricted the good performance of potential mycoherbicides is the need for a long duration of the leaf wetness period for the occurrence of infection (Boyetchko et al., 2002). However, these restrictions can be overcome by methods of artificial inoculation, since the moisture level and inoculation during the leaf wetness period can be increased by the more efficient use of wetness agents or emulsions, or by applying the fungus to gel (Walker and Connick, 1983) or by using granular preparations

(Walker, 1983).

Most of the studies on potential plant mycoherbicides have been based on formulations of fungi species. This means that biological control is set up based on application of fungal spores in concentrations that do not occur in nature. This is the most common strategy to apply mycoherbicides based on these pathogens (Brun et al., 2016). Several studies indicate that fungi of the genus Colletotrichum receive attention as potential mycoherbicides, since they have enzymes that degrade the plant cell walls, suggesting that some of these proteins may have specific roles in plant infection. There is also evidence that both species of Colletotrichum have the ability to produce indole-acetic acid, whose derivatives are wellestablished models of herbicides (Wei et al., 2016).

However, anthracnose caused by species of the genus Colletotrichum is a common and destructive disease in diverse agricultural crops and forest species. Its global occurrence causes significant losses in tropical and subtropical regions (Araújo et al., 2016). Although the genus contains species with different lifestyles, plants can be infected during any stage of development and symptoms appear after colonization of fungi, which is characterized by necrotic lesions in leaves (Villa-Rivera et al., 2017). Therefore, due to the lack of information about its occurrence and aggressiveness, there is a need to determine the susceptibility of plant species to validate the prospection of mycoherbicides, adopting the pathogenicity test proposed by Wapshere (1974), widely used in biological control programs.

In this study, the host range was evaluated using 53 plants, among species and / or varieties included in the test, and only $T$. domingensis was susceptible to $C$. typhae, suggesting high specificity for the analyzed isolate (Supplementary Table 1).
The $C$. typhae isolate obtained in the survey produced symptoms similar to those obtained in the collection areas, with lesions on the leaves, both in the adaxial and abaxial parts, punctiform, yellow with chlorotic halo, becoming necrotic to the center with a light brown color. Based on these results, it can be inferred that this pathogen has effects mainly on the aerial part of $T$. domingensis. Therefore, it is necessary to carry out more studies mainly at the molecular level to confirm its mycoherbicide potential. It should be considered that a mycoherbicide may not necessarily have the same effect on plants as a chemical herbicide. However, these compounds have the potential to provide a competitive advantage for seedling growth through infection and growth retardation of weed seedlings. Therefore, isolation and structural characterization and mode of action of phytotoxins produced by pathogenic fungi for weeds, including aquatic invasive plants, should be investigated (Souza et al., 2017).

Rangel-Peraza et al., (2017) considered submerged aquatic plants as the most problematic, since they drastically reduce water flow, are rapid in invasion of new areas and difficult to manage or control. The perennial growth habit and the formation of monophytic colonies seem to make them the ideal target of chemical control. However, the use of chemical herbicides is often compromised by problems related to the aquatic environment, including dilution and contact time in tap water.

\section{Materials and Methods}

\section{Collection and identification of T. dominguensis pathogenic isolates}

A total of 107 leaf samples from symptomatic $T$. domingensis plants with necrotic spots were collected from flooded areas of the São Francisco and Doce rivers, Brazil, from municipalities of the states of Sergipe (SE), Espirito Santo (ES), Minas Gerais (MG) and Bahia (BA) (Supplementary Table 2). The collected material was packed in polyethylene bags and taken to the Plant Diseases Laboratory, Department of Plant Pathology, Federal University of Viçosa, Viçosa, state of Minas Gerais, Brazil.

Isolates of the collected samples were made and the fragments containing the fungal structures were grown in Petri plates containing Potato Carrot Agar (PCA) culture medium. The isolates were incubated at $25 \pm 3{ }^{\circ} \mathrm{C}$ in the dark for eight days (Villa-Rivera et al., 2014). The identification of organisms at the genus level was carried out using the identification key of Barnett and Hunter (1972), by observations of the structures under a stereoscopic microscope. In order to confirm the pathogenicity of the isolates, they were inoculated inside $T$. dominguensis disease free seedlings produced in a greenhouse, reproducing the symptoms verified in the field. For this, fungal suspensions $\left(2.5 \times 10^{6}\right.$ conidia $\left./ \mathrm{mL}\right)$, plus Tween $80(0.05 \%)$ were used and the inoculation was done by brushing. The plants were then kept in a fog chamber at 25 ㄷ for 48 hours. After that time, they remained in the greenhouse for the evaluation, which was carried out daily, for 30 days. 


\section{Concentrations of Colletotrichum sp. to evaluate the incidence and severity of the disease}

Due to the rapid sporulation in culture medium and the severity of the disease, which was assessed by fast evolution of the symptoms in the inoculated plant, only the cultures of the genus Colletotrichum sp. obtained in the detection test were used. To this end, the isolates were grown in Potato Dextrose Agar (PDA) culture medium and incubated at $25 \pm 1{ }^{\circ} \mathrm{C}$ in the dark for eight days. The identification of the Colletotrichum typhae species was carried out under a stereoscopic microscope, according to descriptions cited by Greene, (1956). The sample was subcultured three times to obtain a pure culture and stored at $5 \pm 1{ }^{\circ} \mathrm{C}$ after characterization of the species for further testing.

Four groups of adult and young plants of $T$. domingensis, arranged in three replicates, we evaluated the severity of the disease, in each replication consisting of a pot with three plants. The leaves were inoculated by brushing the conidial suspensions with $0.05 \%$ Tween 80 fixative, adjusted at four different concentrations (one for each group of plants): $2.5 \mathrm{x}$ $10^{4}, 2.5 \times 10^{5}, 2.5 \times 10^{6}$ and $2.5 \times 10^{7}$ conidia $/ \mathrm{mL}^{-1}$. The experiment was conducted in a humid chamber at $25 \pm 1{ }^{\circ} \mathrm{C}$ at $90 \%$ relative humidity and transferred to a greenhouse after 48 hours. The evaluations were carried out daily, during eight days. Since there is no descriptive or diagrammatic scale of the disease, the severity was evaluated by the percentage of leaf area affected by the symptoms, which was quantified from photocopied detached symptom leaves (Horsfall and Barratt, 1945) using the software Severity.exe., where the injured area was calculated. Thus, it was possible to correlate the symptomatology and leaf morphology with damages caused by the anthracnose disease caused by $C$. typhae.

\section{Influence of temperature on mycelial growth and germination of $C$. typhae conidia}

For evaluation of mycelial growth, $C$. typhae mycelium discs from colonies with eight days of incubation in Vegetable Broth Agar (VBA) medium were placed in Petri plates, containing the same medium, one disc per plate, with five replicates with the experimental unit consisting of two Petri plates incubated at temperatures of $15,20,25,30$ and $35{ }^{\circ} \mathrm{C}$ in the dark. The evaluations were performed daily by measuring the diameter of the colonies in two perpendicular directions, during four days. From the averages we calculated the area below the mycelial growth curve.

To evaluate the conidia germination, a $2.5 \times 10^{6}$ conidia / $\mathrm{mL}$ suspension of $C$. typhae was used. Four aliquots of $50 \mu \mathrm{L}$ were deposited at equidistant points in Petri plates containing agarwater medium scattered with a Drigalski loop. Five replicates were used, each containing two plates. The plates were incubated for eight days under the same conditions of the tests for evaluation of mycelial growth. After this time, aliquots of sterile distilled water were added to each plate. A fungal suspension was prepared by scraping the colonies and 100 spores of each plate were counted with the aid of a hemacytometer and an optical microscope, quantifying, in percentage, how many of these spores were germinated.
Influence of temperature and leaf wetness period on $T$. domingensis infection by $C$. typhae

T. domingensis seedlings were prepared in polyethylene pots with a three liter capacity using coarse sand $(3.0 \mu \mathrm{m})$, organic substrate and Red Latosol (1:1:1; v/v) as substrate. Four groups of fifteen plants of different ages were inoculated with a suspension of $2.5 \times 10^{6}$ spores / $\mathrm{ml}$ by atomization until run-off with P-600 compressor with the "PULVERJET" P-110 pistol. After inoculation, the plants were kept in a humid chamber (wire-frame vessels wrapped with internally moistened plastic) within growth chambers with the following temperatures: 15 , 20,25 and $30 \pm 2{ }^{\circ} \mathrm{C}$. Each group consisted of five subgroups of three plants, which were gradually removed from the wraps after 8, 12, 24 and 48 hours of leaf wetness. A subgroup for each treatment was placed in each growth chamber without being wrapped in plastic (corresponding to zero hour of leaf wetness). After completing 48 hours, all plants were taken to the greenhouse to evaluate the incidence and severity of the disease. Six evaluations were performed at two-day intervals, with the first evaluation on the eighth day after inoculation.

\section{C. typhae host range}

In order to verify the host range of the isolate under study, inoculations were carried out on the species selected according to the phylogenetic centrifugal method, proposed by Wapshere (1974) with modifications. Due to difficulties of obtaining other plants of the same genus and restrictions of the distribution of the Typhaceae family or even of the Typhales order, it was difficult to perform more complete analyzes for this pathogen. Thus, C. typhae inoculation was performed in $T$. domingensis and plants of the same order and related orders of fruit, forest and large crop species (Anacardiaceae, Apiaceae, Araceae, Arecaceae, Asteraceae, Bromeliaceae, Cannaceae, Caricaceae, Chenopodiaceae, Commelinaceae, Cyperaceae, Euphorbiaceae, Euriocaulaceae, Fabaceae, Halaceae, Laceaceae, Malaceae, Mayaceae, Maraceaeae, Musaceae, Myraceceae, Poaceae, Pontederiaceae, Rosaceae, Rubiaceae, Rutaceae, Solanaceae, Sparganiaceae, Strelitzaceae, Typhaceae, Vitaceae, Xyridaceae and Zingiberaceae). Forest species and agricultural crops were included in the evaluation, whether or not related to the target plant, and plants of species susceptible to fungi of the genus Colletotrichum sp., totaling 53 species. Ten leaves of each plant species were inoculated by the $2.5 \times 10^{6}$ conidia $/ \mathrm{mL}^{-1}$ suspension by the brushstroke method and were kept in a humid chamber at $25 \pm 1{ }^{\circ} \mathrm{C}$ with $90 \%$ relative humidity for 48 hours. After this time, they were transferred to a greenhouse and the evaluations to detect the presence or absence of symptoms caused by $C$. typhae were carried out at the $3 \mathrm{rd}, 7$ th and 21st days.

\section{Statistical analysis}

The tests to identify the effect of temperature on mycelial growth and germination of $C$. typhae spores were conducted in a randomized complete design with five replicates, with two Petri plates each, totaling 5 treatments. To evaluate the 
influence of leaf wetness and temperature on $T$. dominguensis infection by $C$. typhae, the trials were conducted in a randomized complete design with 20 treatments and three replicates, each replicate consisting of a pot with three plants. The statistical editor for the analyzes was SAEG.

The effect of the temperatures was evaluated by the analysis of variance and linear regression analysis. The equations were chosen based on the significance of the regression coefficients, adopting the level of $1 \%$ of probability. In the photoperiod effect test, the treatment means were compared by the Tukey test at a significance level of $5 \%$.

In order to evaluate the effect of temperature and leaf wetness on the incidence and severity of the disease, a experiment was conducted in a complete randomized design, with four temperatures and five leaf wetness periods, treated in a factorial scheme with two factors, totaling 40 treatments (temperature and leaf wetness periods) and the data submitted to a linear regression analysis.

\section{Conclusion}

The growth of the $C$. typhae colonies in artificial medium was higher, when they were submitted to temperatures of 25 to 30 oC, whereas for spore germination, there was no photoperiod interference. However, the highest percentage of germination occurred at $20 \stackrel{\mathrm{O}}{ }$. The influence of environmental conditions on the infection in artificially inoculated leaves of $T$. domingensis indicated that the temperature of $15 \stackrel{\circ}{\circ} \mathrm{C}$ and 48 hours of leaf wetness promoted the highest disease incidence, as well as the severity for the same period of leaf wetness. The specificity test showed that $C$. typhae is very specific since it was pathogenic only to $T$. domingensis. This the first report of the occurrence of this pathogen in aquatic macrophytes of this species and in T. domingensis in Brazil.

\section{Acknowledgements}

The authors acknowledge the Fundação de Amparo à Pesquisa e ao Desenvolvimento Científico e Tecnológico do Maranhão FAPEMA.

\section{References}

Araújo NAF, Vieira JDM, Moura MR, Pessoa WRLS, Barguil BM (2016) Pathogenicity and aggressiveness of Colletotrichum gloeosporioides isolates in ornamental pepper. Pesq Agropec Trop. 46(3): 321-326.

Barnett HC, Hunter BB (1972) Illustrated genera of imperfect fungi. 3rd ed. Burgess Publishing, Mineapolis. 241.

Bedendo IP, Amorim L (2011) Ambiente e doença. In: Amorim L, Rezende JAM, Bergamin Filho, A. Manual de Fitopatologia: Princípios e conceitos. 4rd ed, Ceres, São Paulo. 147.

Bonanno G, Cirelli GL (2017) Comparative analysis of element concentrations and translocation in three wetland congener plants: Typha domingensis, Typha latifolia and Typha angustifolia. Ecoto Enviro Saf. 143(5): 92-101.

Boyetchko SM, Rosskopf EN, Caesar AJ, Charudattand R (2002) Biological weed control with pathogens: search for candidates to applications. Appl Mycol Biotechnol. 2(3): 239274.

Brun T, Rabuske JE, Todero I, Almeida TC, Dias Junior JJ, Ariotti G, Confortin T, Arnemann JA, Kuhn RC, Guedes JVC, Mazutti MA (2016) Production of bioherbicide by Phomasp. in a stirred-tank bioreactor. 3 Biotech. 6(2): 1-9.

Cimmino A, Masi M, Evidente M, Superchi S, Evidente A (2015) Fungal phytotoxins with potential herbicidal activity: chemical and biological characterization. Nat Prod Rep. 32(12): 1629-1653.

Couto EF, Menezes M (2004) Physiological and morphological characterization of Colletotrichum musae isolates. Fitopatol Bras. 29(4): 406-412.

Diao YZ, Fan JR, Wang ZW, Liu XL (2013) First report of Colletotrichum boninense causing anthracnose on pepper in China. Plant Dis. 97(1): 138-148.

Doyle VP, Oudemans PV, Rehner SA, Litt A (2013) Habitat and host indicate lineage identity in Colletotrichum gloeosporioides s.l. from Wild and agricultural landscapes in North America. PLoS One, 8(5): e62394.

Estrada AB, Dodd JC, Jeffries P (2000) Effect of humidity and temperature on conidial germination and appressorium development of two Philippine isolates ofthe mango anthracnose pathogen Colletotrichum gloeosporioides. Plant Pathol. 49(5): 608-618.

Garlich N, Cruz C, Silva A, Carraschi SP, Malaspina IC, Pitelli RA, Bianco S (2016) Diquat associated with copper sources for algae control: efficacy and ecotoxicology. J Environ Sci Health B. 1(4): 1-7.

Greene, HC (1956) Notes on Wisconsin parasitic fungi. XXII. Transactions of the wisconsin academy of science and arts. Letters 44(41): 29-43.

Harding DP, Raizada MN (2015) Controlling weeds with fungi, bacteria and viruses: a review. Front Plant Sci. 6(3):1-14.

Heydari A, Pessarakli M (2010) A review on biological control of fungal plant pathogens using microbial antagonists. J Biol Sci. 10(4): 273-290.

Horsfall JG, Barratt RW (1945) An improved grading system for measuring plant diseases. Phytopathol. 35(5): 655.

Jiménez MM, Villasana AM (2009) Evaluation of toxicity of Cercospora piaropi in a mycoherbicide formulation by using bacterial bioluminescence and the Ames mutagenicity tests. Mycopathologia. 167(4): 203-208.

Lagerwall G, Kiker G, Muñoz-Carpena R, Wang N (2017) Accounting for the impact of management scenarios on Typha Domingensis (Cattail) in an everglades wetland. Enviro Manage. 59(1): 129-140.

Kusari S, Hertweck C, Spiteller M (2012) Chemical ecology of endophytic fungi: origins of secondary metabolites. Chem Biol. 19(7): 792-798.

Lima LL, Scaloppi EAG, Barreto LF, Barreto M (2017) Temperatures and leaf wetness duration on orange rust development in sugarcane (Puccinia kuehnii). Summa Phytopathol. 43(2): 132-135.

Malaspina IC, Cruz C, Garlich N, Bianco S, Pitelli, RA (2017) Effectiveness of diquat, both isolated and associated with copper sources in controlling the Hydrilla verticillata submerged macrophytes and ankistrodesmus gracilis microphyte. Planta Daninha. 35(3): 1-8. 
Mckay SF, Freeman S, Minz D, Maymon M, Sedgley M, Collins GC, Scott ES (2009) Morphological, genetic, and pathogenic characterization of Colletotrichum acutatum, the cause of anthracnose of almond in Australia. Phytopathol. 99(8): 985895.

Moral J, Jurado-Bello J, Sánchez, M I, Oliveira R, Trapero A (2012) Effect of temperature, wetness duration, and planting density on olive anthracnose caused by Colletotrichum spp. Phytopathol. 102(10): 974-981.

Oliveira JPV, Pereira MP, Duarte VP, Corrêa FF, Castro EM, Pereira FJ (2017) Cadmium tolerance of Typha domingensis Pers. (Typhaceae) as related to growth and leaf morphophysiology. Braz J Biol. 77(1): 52-59.

Pitelli RLCM, Toffanelli C, Vieira E, Pitelli RA, Velini ED (2008) Dynamics of the aquatic macrophytecommunity in the Santana reservoir in Pirai-RJ. Planta Daninha. 26(3): 473-480.

Poltronieri TPS, Azevedo LAS, Silva DEM (2013) Efeito da temperatura no crescimento micelial, produção e germinação de conídios de Colletotrichum gloeosporioides, isolados de frutos de palmeira Juçara (Euterpe edulis Mart). Summa Phytopathol. 39(4): 281-285.

Pompêo M (2017) Monitoramento e manejo de macrófitas aquáticas em reservatórios tropicais brasileiros. Instituto de Biociências da USP, São Paulo. 138.

Rangel-Peraza JG, Mendivil-García K, Cedillo-Herrera CIG, Rochín-Medina JJ, Rodríguez-Mata A E, Bustos-Terrones YA (2017) Optimization of organic matter degradation kinetics and nutrient removal on artificial wetlands using Eichhornia crassipes and Typha domingensis. Enviro Technol. 15(2): 1-9.

Singh B, Saxena S, Meshram V, Kumar M (2016) Mycoherbicidal potential of Phaeoacremonium italicum, a new pathogen of Eichhornia crassipes infesting harike wetland, India. Mycobiol. 44(2): 85-92.

Soares-Colletti AR, Lourenço SA (2014) Effect of temperature, wetness duration and cultivar on the development of anthracnose in guava fruits. Summa phytopathol. 40(4): 307312.
Soares AR, Lourenço SA, Amorim L (2008) Infecção de goiabas por Colletotrichum gloeosporioides e Colletotrichum acutatum sob diferentes temperaturas e períodos de molhamento. Trop Plant Pathol. 33(4): 265-72.

Smith SM, Newman S (2001) Growth of southern cattail (Typha domingensis Pers.) seedlings in response to fire-related soil transformations in the Northern Florida everglades. Wetlands. 21(3): 363-369.

Souza ARC, Baldoni DB, Lima J, Porto V, Marcuz C, Machado C, Ferraz RC, Kuhn RC, Jacques RJ S, Guedes, JVC, Mazuttia AM (2017) Selection, isolation, and identification of fungi for bioherbicide production. Braz J Microbiol. 48(1): 101-108.

Terefe H, Fininsa C, Sahile S, Tesfaye K (2015) Effect of temperature on growth and sporulation of Botrytis fabae, and resistance reactions of faba bean against the pathogen. $J$ Plant Pathol Microbiol. 6(7): 1-9.

Villa-Rivera MG, Conejo-Saucedo U, Lara-Marquez A, CanoCamacho H, Lopez-Romero E, Zavala-Paramo MG (2017). The Role of Virulence Factors in the Pathogenicity of Colletotrichum sp. Curr Protein Pept Sci. 18(10): 1005-1018.

Walker HL (1981). Granular formulation of Alternaria macrospora for control of spurred anoda (Anoda cristata). Weed Sci. 29(3): 342-345.

Walker HL, Connick WJ (1983) Sodium alginate for production and formulation of mycoherbicides. Weed Sci. 31(4): 333338.

Wapshere AJA (1974) strategy for evaluating the safety of organisms for biological weed control. Ann Apl Biol. 77(5): 201-211.

Wei W, Ying X, Wenjun Z, Nancong W, Guogen Y, Fang P (2016) Colletotrichum higginsianum mitogen-activated protein kinase chmk1: role in growth, cell wall integrity, colony melanization, and pathogenicity. Front Microbiol. 7(3): 12121220. 